\title{
Leigh Disease
}

National Cancer Institute

\section{Source}

National Cancer Institute. Leigh Disease. NCI Thesaurus. Code C84814.

An inherited disorder affecting the nervous system, caused by genetic mutations in the mitochondrial DNA or deficiency of pyruvate dehydrogenase. Signs and symptoms appear in infancy and include loss of the motor abilities, poor sucking abilities, irritability, lack of muscle tone, and seizures. 